\title{
Isolation and Partial Characterization of Structural Components of the Walls of Alkalophilic Bacillus Strain C-125
}

\author{
By RIKIZO AONO \\ Research Institute of Fermentation, Yamanashi University, Kofu, Yamanashi 400, Japan
}

(Received 3 April 1984; revised 30 June 1984)

\begin{abstract}
After trichloroacetic acid extraction of the walls of alkalophilic Bacillus sp. strain C-125 grown at an alkaline or a neutral $\mathrm{pH}$, two acidic structural polymer fractions were isolated by ionexchange chromatography and gel chromatography. One was a teichuronic acid fraction containing $\mathrm{N}$-acetyl-D-fucosamine, glucuronic acid and galacturonic acid in a molar ratio of $1: 1: 1$. This teichuronic acid amounted to $390 \mu \mathrm{g}$ per mg peptidoglycan in the walls of the bacterium grown at an alkaline $\mathrm{pH}$ or $80 \mu \mathrm{g}$ per $\mathrm{mg}$ at a neutral $\mathrm{pH}$. The molecular weight of the teichuronic acid from the cells grown at an alkaline $\mathrm{pH}$ was 70000 compared to a molecular weight of 48000 at a neutral $\mathrm{pH}$ as estimated by gel chromatography. The other fraction contained glucuronic acid and L-glutamic acid in a molar ratio of $1: 5$. This fraction was either a copolymer of both the acids or a mixture of polyglucuronate and polyglutamate. This fraction amounted to $560 \mu \mathrm{g}$ per mg peptidoglycan in the walls of the bacterium grown at an alkaline $\mathrm{pH}$ or $240 \mu \mathrm{g}$ per mg at a neutral $\mathrm{pH}$. The molecular weight of the fraction from both the wall preparations was about 19000 .
\end{abstract}

\section{INTRODUCTION}

We have previously examined the walls of several alkalophilic strains of the genus Bacillus (Aono \& Horikoshi, 1983; Horikoshi \& Akiba, 1982). The strains were divided into three groups on the basis of the chemical composition of the walls together with other physiological characteristics. The alkalophilic strains of Bacillus in group 1 contain teichuronic acid in the walls and cannot grow at a neutral $\mathrm{pH}$. The walls of group 2 organisms contain large amounts of acidic a mino acids and uronic acids. Most strains in group 2 can grow at a neutral $\mathrm{pH}$ but require the presence of sodium ions. The same acidic amino acids and uronic acids are found in much smaller quantities in the walls prepared from bacteria grown at a neutral $\mathrm{pH}$. This indicated that the acidic components in the outermost layer of the group 2 bacteria have a function in supporting growth at an alkaline $\mathrm{pH}$. The strains in group 3 have teichoic acid in their walls.

Bacillus sp. strain C-125 was classified in group 2. The chemical composition of its nonpeptidoglycan components was simple in comparison to that of other strains in group 2 . The non-peptidoglycan components of Bacillus C-125 walls were extracted with trichloroacetic acid and characterized so that the structure and physiological importance of these acidic polymers could be determined.

This paper presents data on the separation and partial characterization of the acidic structural components of the alkalophilic strain of Bacillus $\mathrm{C}-125$ and discusses their possible physiological functions.

\section{METHODS}

Organism and cell wall preparation. The alkalophilic strain of Bacillus $\mathrm{C}-125$ was cultured at an alkaline or a neutral pH as described previously (Aono \& Horikoshi, 1983). The culture medium contained ( $\mathrm{g}$ per litre of deionized water): $\mathrm{K}_{2} \mathrm{HPO}_{+}, 13 \cdot 7 ; \mathrm{KH}_{2} \mathrm{PO}_{+}, 5 \cdot 9$; citric acid. $0 \cdot 34: \mathrm{MgSO}_{4} .7 \mathrm{H}_{2} \mathrm{O}, 0 \cdot 05 ; \mathrm{Na}_{2} \mathrm{CO}_{3}, 10 \cdot 6 ;$ glucose, $5 ;$ peptone, 5 ; yeast extract. I. Glucose and $\mathrm{Na}_{2} \mathrm{CO}_{3}$ were sterilized separately and then added to the medium. The $\mathrm{pH}$ of this medium was 10 . The same medium containing $11 \cdot 7 \mathrm{~g} \mathrm{NaCl}$ instead of $\mathrm{Na}_{2} \mathrm{CO}_{3}$ was adjusted to $\mathrm{pH} 7 \cdot 2$. The organism was grown at $32{ }^{\circ} \mathrm{C}$ aerobically with shaking. Bacteria in the early stationary phase of growth $\left(\mathrm{OD}_{550} 2 \cdot 0-3 \cdot 0\right)$

$0001-187901985$ SGM 
were harvested by centrifugation at $7000 \mathrm{~g}$ for $10 \mathrm{~min}$ at $5{ }^{\circ} \mathrm{C}$ and their walls were prepared as described previously (Aono \& Horikoshi, 1983). Walls from cells grown at pH 10 are referred to as 'alkaline walls', and those from cells grown at $\mathrm{pH} 7 \cdot 2$ as 'neutral walls'.

Trichloroacetic acid extraction of cell wall components. The alkaline $(4680 \mathrm{mg}$ dry wt) and neutral $(1360 \mathrm{mg})$ cell walls were suspended in $5 \%(\mathrm{w} / \mathrm{v})$ trichloroacetic acid (TCA) to a concentration of $15 \mathrm{mg} \mathrm{ml}^{-1}$. The suspensions were incubated at $32{ }^{\circ} \mathrm{C}$ overnight and then centrifuged at $18000 \mathrm{~g}$ for $40 \mathrm{~min}$ at $10^{\circ} \mathrm{C}$. The supernatant liquid was stored at $-20^{\circ} \mathrm{C}$. The insoluble solid was resuspended in $5 \%$ TCA to the original volume and the extraction with TCA was repeated twice more. The TCA extracts were combined and exhaustively dialysed against running water. The non-diffusible material was dialysed against 10 litres of deionized water before being freeze-dried.

Isolation of cell wall components. The non-diffusible fraction $(2500 \mathrm{mg}$ dry wt) from the alkaline walls was dissolved in $170 \mathrm{ml} 50 \mathrm{~mm}$-acetic acid/ $\mathrm{NaOH}$ buffer $(\mathrm{pH} \mathrm{5.0)}$ ) and loaded on a DEAE-cellulose column $(2.5 \times 85 \mathrm{~cm})$ which had been equilibrated with the same buffer. The column was washed with $700 \mathrm{ml}$ of the buffer at a flow rate of $120 \mathrm{ml} \mathrm{h}^{-1}$. The column was eluted at the same rate with $400 \mathrm{ml}$ of the buffer containing $0 \cdot 2 \mathrm{M}-\mathrm{NaCl}$, followed by a linear gradient elution from 0.2 to $0.6 \mathrm{M}-\mathrm{NaCl}$ in the buffer $(1200 \mathrm{ml})$ at a flow rate of $60 \mathrm{ml} \mathrm{h}^{-1}$. Fractions $(12 \mathrm{ml})$ containing uronic acids were pooled, dialysed against running water and freeze-dried. The TCA extracts $(460 \mathrm{mg})$ from the neutral walls were treated in a similar manner.

Fraction A1 ( $760 \mathrm{mg}$, see Results) obtained by DEAE-cellulose chromatography was dissolved in $60 \mathrm{ml} 0 \cdot 2 \mathrm{M}-$ $\mathrm{NaCl}$ and filtered through a membrane filter $(0.04 \mu \mathrm{m})$. Samples $(3 \mathrm{ml})$ of this filtrate were applied to a column of Toyopearl HW55S (2.6 $\times 92 \mathrm{~cm}$; Toyo Soda, Japan, now sold under the name Fractogel TSK-HW55S) which had been equilibrated with $0.2 \mathrm{M}-\mathrm{NaCl}$. The column was eluted with $0.2 \mathrm{M}-\mathrm{NaCl}$ at a flow rate of $30 \mathrm{ml} \mathrm{h}^{-1}$. Fractions $(6 \mathrm{ml})$ were assayed for uronic acids and amino sugars. The fractions containing these substances from a number of gel chromatographies were combined, dialysed against deionized water and freeze-dried.

Fraction A2 (1360 mg, see Results) was dissolved in $40 \mathrm{ml} 0 \cdot 2 \mathrm{M}-\mathrm{NaCl}$ and then filtered. Samples (4 ml) of this filtrate were chromatographed on the Toyopearl HW55S column. The column was eluted in the same way as for fraction Al. Fractions containing glucuronic acid and L-glutamic acid were pooled, dialysed against deionized water and freeze-dried. Fractions N1 $(120 \mathrm{mg})$ and N2 (290 mg, see Results) were treated in a similar manner.

Analyses. (i) Amino acids, uronic acids and phosphorus were determined as described previously (Aono \& Horikoshi, 1983; Aono et al., 1984).

(ii) Cell walls and peptidoglycans were hydrolysed in $4 \mathrm{M}-\mathrm{HCl}$ for $15 \mathrm{~h}$ at $100^{\circ} \mathrm{C}$ in sealed tubes. Samples purified by chromatography were hydrolysed for $5 \mathrm{~h}$. Amino sugars were assayed by the Elson-Morgan reaction (Ashwell, 1957) with glucosamine and fucosamine prepared from the walls of Bacillus C-125 as reference standards. The hydrolysates were also analysed with an amino acid analyser so that each amino sugar could be determined separately.

(iii) Acetic acid was released from samples by hydrolysis with $2 \mathrm{M}-\mathrm{HCl}$ in sealed tubes at $100{ }^{\circ} \mathrm{C}$ for $5 \mathrm{~h}$. Acetate was determined by an acetic acid assay kit from Boehringer, after neutralization of the hydrolysates. Hydrolysis of the $O$-acetyl bond was carried out with $0.015 \mathrm{M}-\mathrm{NaOH}$ at $37^{\circ} \mathrm{C}$ for $1 \mathrm{~h}$ (Perkins, 1965). Acetic acid was determined with the assay kit after neutralization with $0 \cdot 2 \mathrm{M}-\mathrm{HCl}$.

(iv) Sodium ions were determined with a Hitachi atomic absorption spectrometer model 170-30.

(v) Reducing groups were determined with ferricyanide (Park \& Johnson, 1949).

(vi) Molecular weights of samples were tentatively determined by gel chromatography on a colurnn $(1.5 \times$ $94 \mathrm{~cm}$ ) of Toyopearl HW55S in $0.3 \mathrm{M}-\mathrm{NaCl}$ at a flow rate of $30 \mathrm{ml} \mathrm{h}^{-1}$. Fractions $(1 \mathrm{ml})$ were collected and assayed for uronic acids. The void volume was determined using blue dextran 2000 (Pharmacia). Dextrans T-10, T-40 and $\mathrm{T}-70$ (Pharmacia) were used as molecular weight standards. Elution volumes of the dextrans were determined with the anthrone reagent (Ashwell, 1957).

(vii) Viscosities of the wall suspensions were measured with an Ostwald viscometer at $28^{\circ} \mathrm{C}$. The walls were suspended in deionized water.

Thin-layer chromatography. Ascending chromatograms were run on Avicel cellulose thin-layer at room temperature in the following solvents: (A) ethyl acetate/pyridine/water/acetic acid $(5: 5: 3: 1$, by vol.); (B) phenol $/ 1 \%$ (aqueous) ammonia $(5: 2, \mathrm{v} / \mathrm{v})$. The components of the samples were located with alkaline silver nitrate or ninhydrin spray. Authentic standards used were glucosamine. $\mathrm{HCl}$, glutamic acid, glucuronic acid and galacturonic acid (Wako Pure Chemical, Osaka, Japan).

Electrophoresis. Samples were spotted in the middle of a Whatman no. 1 filter paper and electrophoresed in $10 \%$ acetic acid/pyridine buffer $\left(\mathrm{pH} \mathrm{2 \cdot 8)}\right.$ at $17 \mathrm{~V} \mathrm{~cm}^{-1}$ for $4 \mathrm{~h}$.

\section{RESULTS}

\section{Preparation and composition of cell walls}

Large amounts of L-glutamic acid and glucuronic acid were found in the alkaline walls as described previously (Aono \& Horikoshi, 1983). Galacturonic acid and fucosamine (see below) 
Table 1. Composition of cell walls from alkalophilic Bacillus C-125.

\begin{abstract}
Analyses were carried out as described in Methods. Samples were hydrolysed in $6 \mathrm{M}-\mathrm{HCl}$ at $105^{\circ} \mathrm{C}$ for $16 \mathrm{~h}$ to determine amino acids. For determination of amino sugars, samples were hydrolysed in $4 \mathrm{M}-\mathrm{HCl}$ at $100^{\circ} \mathrm{C}$ for $15 \mathrm{~h}$ and analysed with the amino acid analyser. The determination is not corrected for destruction during the acid hydrolysis. Reducing groups are represented as glucosamine. Values refer

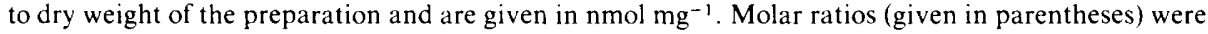
calculated taking diaminopimelic acid as $1.0, \mathrm{NT}$, Not tested.
\end{abstract}

\section{Component}

Muramic acid

Glutamic acid

L-isomer

D-isomer

Alanine

Diaminopimelic acid

Glucosamine

Galactosamine or mannosamine

Fucosamine

Glucuronic acid

Galacturonic acid

Phosphorus

Reducing groups

$\begin{array}{cc}\begin{array}{c}\text { Alkaline } \\ \text { cell wall }\end{array} & \begin{array}{c}\text { Neutral } \\ \text { cell wall }\end{array} \\ 284(0 \cdot 63) & 680(0 \cdot 95) \\ 1980(4 \cdot 4) & 1830(2 \cdot 6) \\ 1540(3 \cdot 4) & 1050(1 \cdot 5) \\ 440(0 \cdot 98) & 780(1 \cdot 1) \\ 633(1 \cdot 4) & 1040(1 \cdot 5) \\ 451(1 \cdot 0) & 714(1 \cdot 0) \\ 273(0 \cdot 61) & 553(0 \cdot 77) \\ 45(0 \cdot 10) & 32(0 \cdot 05) \\ 234(0 \cdot 52) & 41(0 \cdot 06) \\ 652(1 \cdot 4) & 301(0 \cdot 42) \\ 324(0 \cdot 72) & 110(0 \cdot 15) \\ 25(0 \cdot 06) & 15(0 \cdot 02) \\ 2(0 \cdot 004) & 1(0 \cdot 001)\end{array}$

$\begin{array}{cc}\begin{array}{c}\text { Alkaline } \\ \text { peptidoglycan }\end{array} & \begin{array}{c}\text { Neutral } \\ \text { peptidoglycan }\end{array} \\ 1120(0 \cdot 97) & 1180(1 \cdot 1) \\ 1320(1 \cdot 2) & 1100(1 \cdot 0) \\ 50(0 \cdot 04) & 10(0 \cdot 01) \\ 1270(1 \cdot 1) & 1090(1 \cdot 0) \\ 1720(1 \cdot 5) & 1620(1 \cdot 5) \\ 1150(1 \cdot 0) & 1050(1 \cdot 0) \\ 974(0 \cdot 85) & 915(0 \cdot 87) \\ 0(0) & 0(0) \\ 0(0) & 0(0) \\ 11(0 \cdot 01) & 2(0 \cdot 002) \\ \text { NT NT } & \text { NT NT } \\ 60(0.05) & 60(0.06) \\ \text { NT NT } & \text { NT NT }\end{array}$

were present in large amounts whereas small amounts of these substances were found in the neutral walls (Table 1). Reducing groups were very low in both preparations of the walls in comparison to the amounts of glucosamine and muramic acid, indicating that hydrolysis of the walls by autolytic enzymes was minimal during wall preparation. A suspension of the alkaline walls was more viscous than that of neutral walls. The intrinsic viscosity of the walls was 88 (alkaline) or 46 (neutral) $\mathrm{ml} \mathrm{g}^{-1}$ in deionized water. The $\mathrm{OD}_{550}$ of the wall suspension $\left(1 \mathrm{mg} \mathrm{ml}^{-1}\right)$ was $0 \cdot 31$ (alkaline) or 0.49 (neutral) in $20 \mathrm{~mm}$-phosphate buffer ( $\mathrm{pH} 7.0$ ). The differences in the physical characteristics of the walls may be caused by differences in the amounts of non-peptidoglycan components.

\title{
Fractionation of non-peptidoglycan components
}

Extraction with TCA three times solubilized $97 \%$ of uronic acids and $93 \%$ of L-glutamic acid found in the alkaline walls. Materials solubilized with TCA amounted to $57 \%$ (alkaline walls) or $38 \%$ (neutral walls) of the original dry weight. The composition of the insoluble materials after treatment with TCA at $60^{\circ} \mathrm{C}$ is shown in Table 1 .

The non-dialysable fraction ( $2500 \mathrm{mg} \mathrm{dry} \mathrm{wt}$ ) of the TCA extracts from the alkaline walls was separated into two fractions by DEAE-cellulose column chromatography (Fig. 1). Fraction A1 eluted at $0 \cdot 29-0 \cdot 35 \mathrm{M}-\mathrm{NaCl}$ and contained uronic acids and fucosamine as major components (760 mg). The other fraction (A2) eluted at $0 \cdot 40-0 \cdot 48 \mathrm{M}-\mathrm{NaCl}$ and contained L-glutamic acid and glucuronic acid as major components $(1600 \mathrm{mg})$. The non-diffusible fraction $(460 \mathrm{mg})$ from the neutral walls was also separated into two fractions when eluted with the same concentrations of $\mathrm{NaCl}$ as above. Fractions $\mathrm{N} 1(120 \mathrm{mg}$ dry wt) and $\mathrm{N} 2(290 \mathrm{mg})$ contained, respectively, similar components to fractions $\mathrm{A} 1$ and $\mathrm{A} 2$. The fractions, especially $\mathrm{A} 1$ and $\mathrm{N} 1$, gave very viscous solutions and attempts to purify them by gel chromatography were unsuccessful because of this. The fractions were then dissolved in a comparatively large volume of $0.2 \mathrm{M}-\mathrm{NaCl}$ and samples were subjected to gel chromatography on Toyopearl HW55S. Fraction Al gave a single peak composed of uronic acids and fucosamine, and was assumed to be a teichuronic acid (Fig. 2a). Carbazole positive fractions from a number of gel chromatographies were combined and desalted. Fraction $\mathrm{N} 1$ gave a similar single peak. Fraction A2 yielded a single overlapping peak composed of glucuronic acid and L-glutamic acid (Fig. $2 b$ ). Fraction N2 yielded a single peak similar to that of fraction A2. 


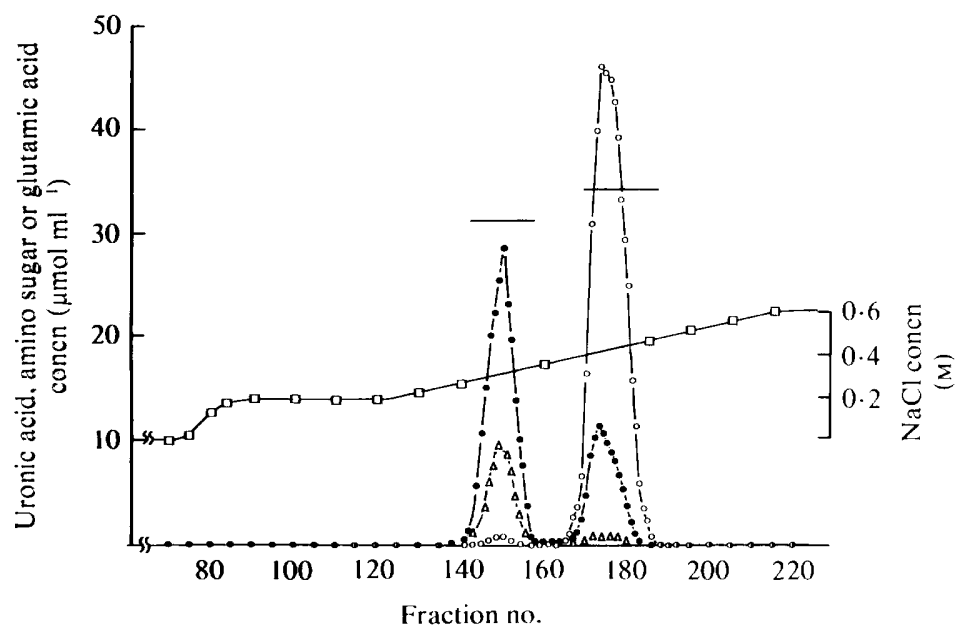

Fig. 1. DEAE-cellulose chromatography of the non-dialysable fraction of TCA extracts. The non-dialysable fraction of TCA extracts from the alkaline walls were dissolved in $50 \mathrm{~mm}$-acetic acid $/ \mathrm{NaOH}$ buffer $(\mathrm{pH} 5.0)$ and loaded on a column $(2.5 \times 85 \mathrm{~cm})$ of DEAE-cellulose equilibrated with the same buffer. The column was eluted as described in Methods. Fractions $(12 \mathrm{ml})$ were collected and assayed for uronic acids $(\bigcirc)$, amino sugars $(\triangle)$, L-glutamic acid $(O)$ and $\mathrm{NaCl}(\square$ ). Fractions $142-157$ (fraction A1) and 168-186 (fraction A2) were pooled.
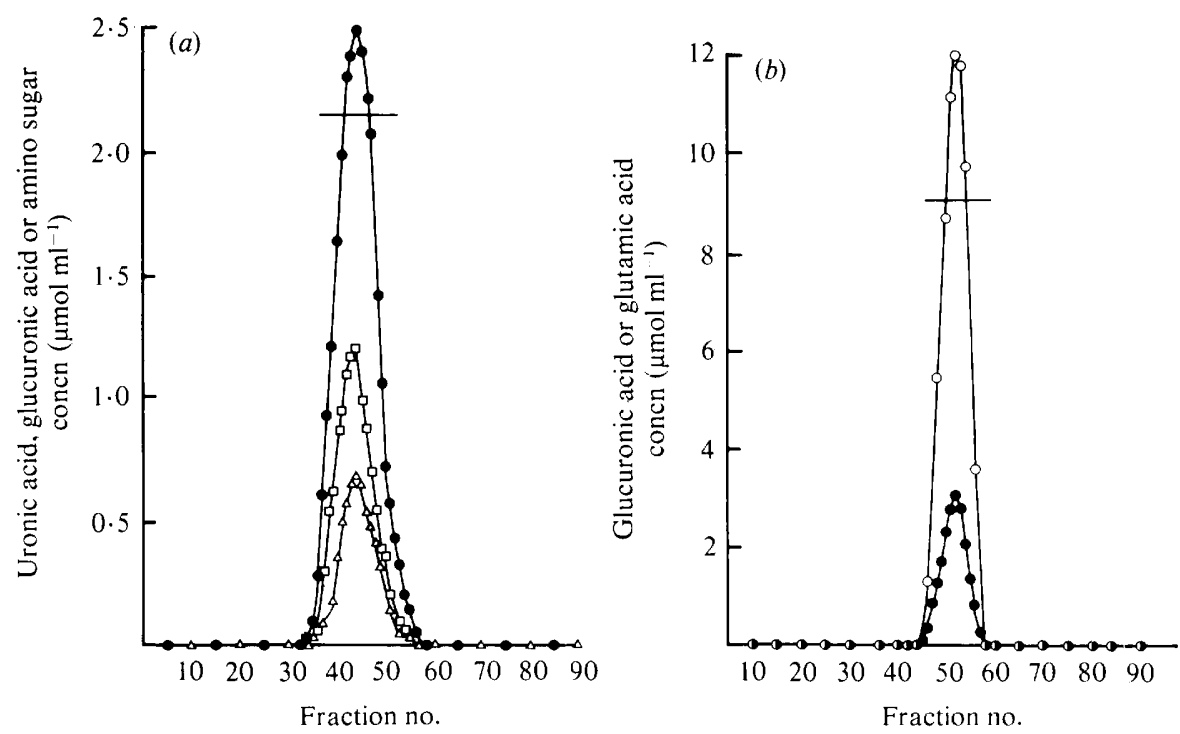

Fig. 2. Elution of fractions A1 and A2 through a column of Toyopearl HW55S. Fractions A1 (a) and A2 (b) were separated by DEAE-cellulose chromatography, dissolved in $0.2 \mathrm{M}-\mathrm{NaCl}$ and chromatographed on a column $(2.6 \times 92 \mathrm{~cm})$ of Toyopearl HW55S as described in Methods. Fractions $(6 \mathrm{ml})$ were collected and assayed for uronic acids $(\bigcirc)$, glucuronic acid $(\square)$, amino sugars $(\triangle)$ and L-glutamic acid $(\bigcirc)$.

\section{Composition of teichuronic acid}

Fraction $\mathrm{Al}$ was hydrolysed with various concentrations of $\mathrm{HCl}$ at $100{ }^{\circ} \mathrm{C}$ for $1 \mathrm{~h}$. These hydrolysates $(10 \mu \mathrm{g})$ were subjected to cellulose thin-layer chromatography in solvent $\mathrm{A}$. Alkaline silver nitrate revealed several spots of $R_{F} 0 \cdot 82$ (1), $0 \cdot 44$ (2), $0 \cdot 21$ (3) and $0 \cdot 18$ (4). Spots 1 , 3 and 4 , respectively, corresponded to the authentic lactone form of glucuronic acid, free acid 
Table 2. Composition of fractions purified by DEAE-cellulose and gel chromatography.

The experimental details are described in Methods. Values are $\mu \mathrm{mol} \mathrm{mg}^{-1}$. Molar ratios (given in parentheses) were calculated taking glucuronic acid as 1.0. ND, Not detected.

Component

Glucuronic acid

Galacturonic acid

Fucosamine

Galactosamine or mannosamine

L-Glutamic acid

Acetic acid

Sodium

Phosphorus
Fraction $\mathrm{Al}$

\begin{tabular}{ll}
1.6 & $(1.0)$ \\
1.5 & $(0.94)$ \\
1.3 & $(0.81)$ \\
ND & \multicolumn{1}{c}{$\mathrm{ND}$} \\
0.004 & $(0.002)$ \\
1.3 & $(0.81)$ \\
2.8 & $(1.8)$ \\
0.0008 & $(0.0005)$
\end{tabular}

\begin{tabular}{ll}
\multicolumn{2}{c}{ Fraction N1 } \\
1.6 & $(1.0)$ \\
1.7 & $(1.1)$ \\
1.4 & $(0.88)$ \\
ND & \multicolumn{1}{c}{ ND } \\
0.006 & $(0.004)$ \\
1.1 & $(0.69)$ \\
2.7 & $(1.7)$ \\
0.0002 & $(0.0001)$
\end{tabular}

Fraction $\mathrm{A} 2$

$\begin{array}{ll}0.96 & (1.0) \\ \text { ND } & \text { ND } \\ 0.004 & (0.004) \\ 0.039 & (0.04) \\ 4.4 & (4.6) \\ 0.097 & (0.10) \\ 4.2 & (4.4) \\ 0.0009 & (0.0009)\end{array}$

Fraction $\mathrm{N} 2$

$0.90 \quad(1.0)$

ND ND

$0.003 \quad(0.003)$

$0.040 \quad(0.04)$

$4 \cdot 3 \quad(4 \cdot 8)$

$0.071 \quad(0.08)$

$4 \cdot 3 \quad(4 \cdot 8)$

$0.001 \quad(0.001)$

form of glucuronic acid and galacturonic acid. Spot 2 also reacted with ninhydrin. Some fainter spots with lower $R_{F}$ values were considered to be oligomers of the compounds described above. Similar results were obtained by chromatography in solvent $B$. The presence of galacturonic acid was confirmed by electrophoresis. About twice the amounts of total uronic acids were obtained in comparison to the amount of glucuronic acid. These results indicated the presence of galacturonic acid and glucuronic acid in almost equal amounts in fractions $\mathrm{Al}$ and $\mathrm{N} 1$. The identity of spot 2, however, was not known. This compound was purified into crystalline form from hydrolysate of fraction A 1. Analysis of $400 \mathrm{MHz}$ NMR revealed it to be fucosamine, and it was shown to be present in the D-form by measurement of its optical rotation (data not shown). Acetic acid was determined after acid hydrolysis and was almost equal to the fucosamine content. No acetate was detected in the fractions treated with dilute $\mathrm{NaOH}$. These results suggested that the amino group of fucosamine was acetylated. The analyses (Table 2) of the fractions Al and N1 accounted for about $90 \%$ of the dry weight of the preparations. It was concluded that the two fractions were identical in composition. Glucuronic acid, galacturonic acid, fucosamine, acetic acid and sodium were found in an approximate molar ratio of $1: 1: 1: 1: 2$. The teichuronic acid was composed of repeating galacturonic acid, glucuronic acid and $\mathrm{N}$-acetyl-D-fucosamine and was obtained as the sodium salt of the hexuronates. Assuming that the composition of the teichuronic acid in the walls was identical to that of the acid purified, the amount of the teichuronic acid in the walls could be calculated on the basis of the galacturonic acid content. The amount of free teichuronic acid was 390 (alkaline walls) or 80 (neutral walls) $\mu \mathrm{g}$ per mg peptidoglycan.

\section{Composition of polymer(s) of glutamate and glucuronate}

Fraction A2 was hydrolysed and analysed by chromatography in the same way as fraction A1. Alkaline silver nitrate revealed two main spots, corresponding to the lactone or free acid form of glucuronic acid. Other uronic acids were absent. A major spot revealed by ninhydrin corresponded to glutamic acid $\left(R_{F} 0 \cdot 13\right)$. Fainter spots with lower $R_{F}$ values were revealed by ninhydrin and were thought to be oligomers containing glutamic acid with a free amino group. Fraction A2 was hydrolysed in $6 \mathrm{M}-\mathrm{HCl}$ at $100^{\circ} \mathrm{C}$ for $25 \mathrm{~h}$. Glutamic acid in the hydrolysate was determined by L-glutamate dehydrogenase and in the amino acid analyser. D-Glutamic acid was not detected. A small amount of $N$-acetyl groups were detected but no $O$-acetyl groups. Small amounts of galactosamine or mannosamine were also present. These amino sugars could not be separated under the conditions used. A trace amount of fucosamine was found. The analyses (Table 2) of the fractions accounted for about $85 \%$ of the dry weight. Glucuronic acid, glutamic acid and sodium were found in an approximate molar ratio of $1: 5: 4$ or 5 . Fractions A2 and N2 had the same composition as each other. However, the chemical nature of the polymer(s) was not clear. The content of L-glutamic acid could permit calculation of an amount of the polymer(s) in the walls. The amount of the free acidic polymer(s) should be 560 (alkaline walls) or 240 (neutral walls) $\mu \mathrm{g}$ per mg peptidoglycan. 


\section{Molecular weights of the preparations}

The molecular weights of the acidic polymers were determined by comparison to the dextrans as standards. Fractions $\mathrm{Al}$ and $\mathrm{N} 1$ were eluted with a broad distribution from the Toyopearl HW55S column. The molecular weight of fraction A1 was distributed between 23000 and 103000 . A value of 70000 was obtained for a peak eluted from the column. The molecular weight of fraction N1 was distributed between 20000 and 95000 . The molecular weight of the peak was estimated as 48000 . Sharp peaks for fractions A2 and N2 were eluted from the column. The molecular weight was 19000 in both the fractions.

\section{Detection of peptidoglycan component}

Fractions A1 and A2 were hydrolysed with $6 \mathrm{M}-\mathrm{HCl}$ at $100^{\circ} \mathrm{C}$ for $20 \mathrm{~h}$. The hydrolysates were analysed with the amino acid analyser. A minor peak corresponding to muramic acid-6-phosphate was found in both the hydrolysates $\left(0.007 \mu \mathrm{mol} \mathrm{mg} \mathrm{m}^{-1}\right.$ in fraction A1 and $0.005 \mu \mathrm{mol} \mathrm{mg}^{-1}$ in fraction A2). Also, trace amounts of muramic acid, alanine and glucosamine were found in the hydrolysates, although the presence of diaminopimelic acid and D-glutamic acid was not established.

The walls could be solubilized with lysozyme. Acidic polymers were eluted together with minor amounts of phosphorus and diaminopimelic acid (data not shown). These results suggested that the polymer(s) of glutamate and glucuronate probably link covalently to the peptidoglycan, as well as the teichuronic acid, but that they probably do not represent capsular material.

\section{DISCUSSION}

The analyses (Table 1) of the neutral walls of the alkalophilic strain of Bacillus C-125 accounted for $82 \%$ of the dry weight of the preparation assuming that all of the amino sugars were $\mathrm{N}$-acetylated. On the other hand, $72 \%$ of the dry weight of the alkaline walls was accounted for by the analyses. The differences in the accountable dry weights were thought to be due to the following. First, uronic acids and glutamic acid should exist as sodium salts. Second, determination of glucosamine and muramic acid was low in comparison to the amount of diaminopimelic acid. Release or recovery of both the sugars after acid hydrolysis might be low in the alkaline walls since approximately equal amounts of glucosamine, muramic acid and diaminopimelic acid were found in the alkaline peptidoglycan.

The non-peptidoglycan components were solubilized with $5 \%$ TCA effectively, although TCA extraction was known to cause partial degradation of teichuronic acids (White \& Gilvarg, 1977). In fact, the molecular weight of teichuronic acid showed a broad distribution, although it was not known to what degree the preparations were hydrolysed during TCA extraction. At least, most of the L-glutamic acid and uronic acids were recovered in the non-dialysable fraction of TCA extracts. As far as they were examined, the peptidoglycan moieties were hardly hydrolysed under the conditions.

The acidic non-peptidoglycan components were separated into two fractions. One was a teichuronic acid, the existence of which had not been shown in the walls of the organism previously (Aono \& Horikoshi, 1983). The other was presumed to be either a copolymer of L-glutamic acid and glucuronic acid, or a mixture of polyglutamate and polyglucuronate. So far, attempts to further separate the fraction chromatographically between polyglutamate and polyglucuronate fractions have been unsuccessful. The values of the molecular weight might not be correct. The molecular references used were dextrans which are roughly spherical molecules. The teichuronic acid and the polymer(s) were highly negatively charged and should be linearly extended molecules which might behave on gel filtration like spherical molecules of higher molecular weight. Some other influences such as ion exclusion and hydration effects must also be considered. The following conclusion, however, can be made. The teichuronic acid was present in the walls of the organism without regard to culture $\mathrm{pH}$. The length of the acid may be increased by culturing the strain at an alkaline $\mathrm{pH}$. Also, the polymer(s) of glutamate and glucuronate exist at the cell surface, regardless of culture $\mathrm{pH}$. The amounts of the polymer(s) could be increased by cultivation at an alkaline $\mathrm{pH}$. 
The cells of Bacillus C-125 are shaped by the A1 $\gamma$ type of peptidoglycan (Aono et al., 1984) and the petidoglycan is enclosed by the acidic polymers with highly negative charges. The author assumes that the negative charges on the acidic non-peptidoglycan components give the cell surface its ability to adsorb sodium and hydronium ions and repulse hydroxide ions, and as a result could enable the cells to grow in an alkaline environment.

The author thanks Dr K. Horikoshi of the Institute of Physical and Chemical Research, Wako, Japan, for helpful discussion, Dr M. Uramoto of the Institute for kind operation of identification of fucosamine by NMR and M. Chijimatsu of the Institute for excellent analysis of amino acids and amino sugars by the amino acid analyser.

\section{REFERENCES}

Aono, R. \& Horikoshi, K. (1982). Chemical composition of cell walls of alkalophilic strains of Bacillus. Journal of General Microbiology 129, 1083 1087.

Aono, R., Horikoshi, K. \& Goto, S. (1984). Composition of the peptidoglycan of alkalophilic Bacillus spp. Journal of Bacteriology 157, 688-689.

AsHWELL, G. (1957). Colorimetric analysis of sugars. Methods in Enzymology 3, 73-105.

HorikoshI, K. \& AkIBA, T. (1982). Cell surface. In
Alkalophilic Microorganisms, pp. 75-77. Heidelberg: Springer-Verlag.

PARK, J. T. \& Johnson, M. J. (1949). A submicrodetermination of glucose. Journal of Biological Chemistry 181, 149-151.

PERKINS, H. R. (1965). The action of hot formamide on bacterial cell walls. Biochemical Journal 95, 876-882.

White, P. J. \& Gilvarg, C. (1977). A teichuronic acid containing rhamnose from cell walls of Bacillus megaterium. Biochemistry 16, 2428-2435. 